\title{
Proceeding
}

Supplementary Issue: Winter Conferences of Sports Science. Costa Blanca Sports Science Events, 22-23 March 2021. Alicante, Spain.

\section{Rhythm and movement in developmental age}

\author{
MARIANNA LIPAROTI $\triangle$, ROBERTA MININO \\ Department of Motor Sciences and Wellness, University of Naples "Parthenope", Italy
}

\begin{abstract}
Coordination is the neurophysiological activity of regulating the synchronism and extent of contraction and relaxation of the various muscles in order to achieve more or less complex movements in pursuit of set goals. Coordinated gestures are characterised by a correct rhythm of movement. The relationship between Movement and Rhythm, is of extreme importance for several reasons. On a biological level, rhythmic capacity leads to a reduction in muscular fatigue, frees us from unnecessary effort, and optimises movement by reducing energy expenditure. Furthermore, rhythmicity develops a series of motor and cognitive skills, which are fundamental for improving the activities of daily life of everyone. The purpose of this work was to investigate articles in the literature that explore the relationship between rhythmicity and motor and cognitive development in school-aged children, and the benefits of improving this motor skill. It has been widely demonstrated that rhythmic training improves coordination, sense of direction, laterality and organisation of space and time, reading, language, logical and mathematical thought structure and socialisation. The development of this special coordinative ability has also been shown to be crucial in children with learning disabilities and in neurodevelopmental disorders. Therefore, education and training in Rhythm is fundamental for learning motor and cognitive development throughout each child's developmental years.
\end{abstract}

Keywords: Rhythm; Movement; Special coordinative ability; Developmental age.

\section{Cite this article as:}

Liparoti, M., \& Minino, R. (2021). Rhythm and movement in developmental age. Journal of Human Sport and Exercise, 16(3proc), S930-S937. https://doi.org/10.14198/ihse.2021.16.Proc3.10

\footnotetext{
Corresponding author. Department of Motor Sciences and Wellness, University of Naples "Parthenope", Italy. https://orcid.org/0000-0003-2192-6841

E-mail: marianna.liparoti@uniparthenope.it

Abstract submitted to: Winter Conferences of Sports Science. Costa Blanca Sports Science Events, 22-23 March 2021. Alicante, Spain.

JOURNAL OF HUMAN SPORT \& EXERCISE ISSN 1988-5202.

(C) Faculty of Education. University of Alicante.

doi:10.14198/jhse.2021.16.Proc3.10
} 


\section{INTRODUCTION}

Movement is defined as the ability to move different body segments in space. The combination of several movements define a motor act, which is characterized by a purpose. The programmed sequence of motor acts, characterized by a general purpose, is called motor action. Motor action are more efficient, Motor actions are more efficient, the more the structures that execute them are developed. These structures, commonly referred to as motor skills, are the physical qualities that each of us possesses that allow us to perform any gesture. They allow the subject to express effective and conscious motor actions, the more complex the more advanced the degree of development and performance achieved. Motor skills are divided into conditional and coordinative skills (Casolo, 2002). The former are mainly determined by energy and metabolic processes, and are Speed, Strength and Resistance. Coordinative skills, on the other hand, are those useful for the organisation and movement control. These in turn are divided into General Coordination Skills (GCC) and Special Coordination Skills (SCC). The first are: Motor Learning (which allows the subject to learn a motor gesture by performing or observing it), Motor Control (which allows the subject to manage and regulate the motor gesture according to the performance to be executed), and Adaptation and Transformation of movements (which allows the subject to adapt his gesture according to external situations without altering the result). The Special Coordinative Skills are: Balance, Orientation, Motor Imagination, Motor Combination, Motor Differentiation and Rhythm.

In the first years of life, a child is able to perform basic movements, which are also called basic motor patterns (Wickstrom, 1975). It is only later, between the ages of 6 and 11, that coordinative skills are developed. Since these skills are not innate, they are closely related to children's experiences and how they move within the environment. The correct development of coordination skills enables more effective learning of more complex motor and cognitive skills (Weineck, 1983). Large differences have been noted between children who were trained in coordination and those who were not, during the years before primary school (Pietsch et al., 2017). A lack of coordination skills is due not only to negative genetic predispositions, but also to a lack of stimulation during the early years of growth, which is why they need to be stimulated in the early school years (Montuori et al., 2019; Palma and Tafuri, 2016; Sorrentino et al., 2019). Rhythmic abilities also depend on the state of a person. Indeed with advancing age and in same pathological conditions (such as in Parkinson, multiple sclerosis, Gaucher, Alzheimer and spastic paraparesis diseases) these abilities could be reduced (Agosti et al., 2016; Jacini et al., 2018; Liparoti et al., 2019; Rucco et al., 2019; Sorrentino et al., 2016). The greater the experience associated with rhythmic skills, the better can be the ability of the subjects to maintain a reserve of these skills.

The learning of these skills can be observed either through the use of specific tests of the subjects' rhythmic abilities, or through the use of sophisticated instruments, such as 3D motion analysis systems, capable of measuring the ability to learn and improve rhythmic skill (Liparoti et al., 2020; Minino et al., 2020; Rucco et al., 2020, 2018).

\section{Rhythm}

Rhythm can be defined as the organisation of temporal, periodic and non-periodic phenomena that follow each other in their own duration and are perceived as a form of whole.

Movement, in all its expressions, is characterised by temporal sequences that, depending on how they are experienced, highlight harmonious or awkward attitudes. Having good coordination in terms of movement is a condition that we find in many moments of our daily life. For example, chewing or walking, which are activities that we perform daily, are voluntary rhythmic motor behaviours. 
Perceiving a stimulus, processing it and producing a response in terms of motor actions, is a process that every human being carries out to produce an adequate movement with a specific purpose. We can find this difference in movements in everyday life as well as in sports. It has been widely demonstrated that an acoustic stimulus is able to improve static and dynamic balance in adults in physiological conditions, as well as in some pathologies (Troisi Lopez et al., 2021; Minino et al., 2020).

The relationship between Movement and Rhythm, especially during a sport activity, is of extreme importance in the acquisition and execution of motor gestures. Rhythmic education is presented as movement education, developing coordination, sense of orientation, laterality, organisation of space and time, reading, logical and mathematical thinking and socialisation. Therefore, rhythm education and training is fundamental for the motor and cognitive development of each child.

Weineck, in his training manual, first defines the general capacity of coordination according to which it is determined above all by the processes of control and regulation of movement and which allows each individual to manage motor actions during predictable or unpredictable situations (Weineck, 1983). At the same time, these actions can be performed more economically in terms of energy and motor skills can be learned more quickly.

Among the first researchers of Rhythm Pedagogy, Emile-Jacques Dalcroze, a teacher and musician, devised a new method of music education through Rhythm Education (Jaques-Dalcroze, 2014). Dalcroze stated that the most effective way to achieve full understanding of music is to make rhythm through kinaesthetic activities. The body is therefore what enables the interiorisation of sound. His didactic method was oriented towards the development of creativity and improvisation through the use of percussion instruments, the voice and the body, motivating students to actively participate in his didactic proposals, thus encouraging a greater awareness of themselves and their bodies (Seitz, 2005). Dalcroze brought this new way of teaching also to dance, taking an interest in the emotional interpretation of dancers, in addition to technique.

Therefore, through the choice of some motor proposals, it is possible to develop the perception of rhythm through the organisation and agreement of personal body rhythms with those of one or more companions, with or without the use of instruments, on a musical theme. The aim of this paper is to investigate the importance of the development of these special coordinative skills in children, in order to improve cognitive and motor development.

\section{METHODS}

A literature search was conducted to identify articles potentially relevant to the purpose of this work, related to the importance of rhythm in children in order to develop cognitive and motor skills useful in daily life. The databases used were PubMed, Scopus and Google Scholar, using the following keywords: motor skills, coordinative and conditioning skills, children, rhythmicity and movement. The total number of articles included in the work was selected through the following inclusion criteria: 1) Articles referring to a population of children of school age to adolescence; 2) Children without any hearing impairment and musculoskeletal or neurological diseases.

\section{RESULTS}

The search of the databases considered for this work found a total of 127 articles (Thirty-one on PubMed, twenty-eight on Scopus and sixty-nine on Scholar). 
After an initial phase of eliminating duplicate articles, a further sorting phase followed, after reading the titles and abstracts of the papers. After reading the full texts of these articles, other thirty-three papers were excluded due to non-compliance with the inclusion criteria.
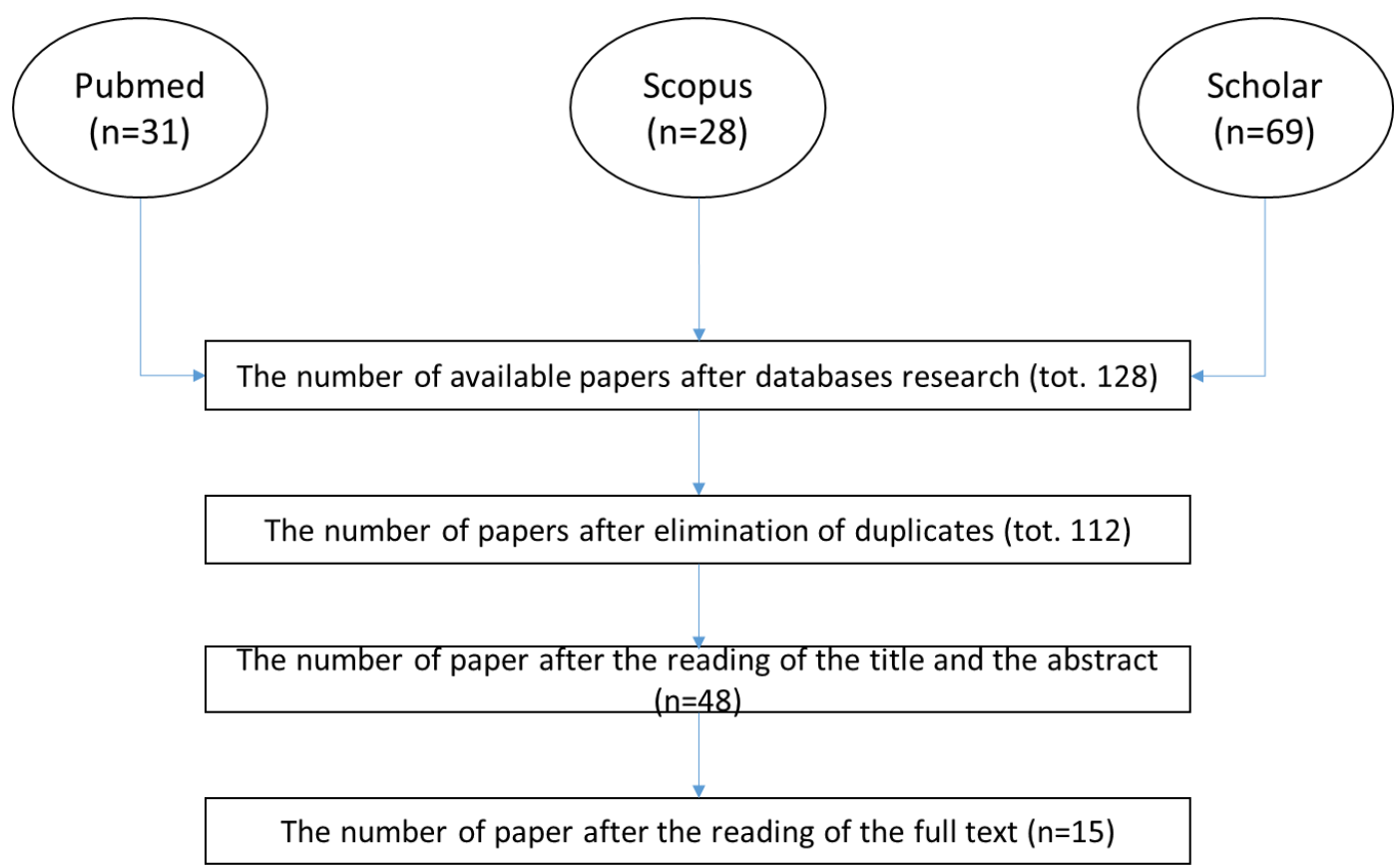

apers after databases research (tot. 128)

The number of papers after elimination of duplicates (tot. 112)

The number of paper after the reading of the title and the abstract $(n=48)$

Figure 1. The Flow chart of literature screening.

\section{DISCUSSION}

Rhythm plays a fundamental role in education, both as a highly socializing moment and because it encourages the control of psychomotor skills, constituting the initial support for every activity.

A key role in learning rhythm and motor coordination is played by music. Like motor activity, music plays an important role in a child's development (Hyde et al., 2009; Schlaug et al., 2005). The benefits of sport for children are frequently spoken about (Boreham and Riddoch, 2001), but music has also been shown to have a positive influence on cognitive skills, listening and the sense of rhythm (Hallam, 2010). Thanks to music, children are more responsive to new information and have faster learning times than those who have never attended music classes.

Several studies since the Second World War have addressed the importance of music and rhythm in the lives of each individual, especially children. In childhood, musical activities improve reading and word recognition skills because using two hands activates the visual cortices of both cerebral hemispheres (Moreno et al., 2009). Listening also offers advantages, as rhythm and melodies can have a positive effect on concentration (Lardone et al., 2018). The Pillsbury studies were the proponents of a new field of research, which at that time was still unexplored, studying spontaneous musical behaviour in pre-school children (Moorhead and Pond, 1978). Zentner and Eerola et al., much more recently, investigated the ability of children aged from 5 to 24 months to move spontaneously in the presence of music, even if not yet in time (Zentner and Eerola, 2010). 
This ability improves over the years and is a useful process in the development of the child's motor and cognitive skills. It has been shown that synchronization ability is closely linked to the development of language ability. In fact, Woodruff Carr et al., show that an increased ability to synchronize a pre-school child's handclap with a rhythm or acoustic stimulus is linked to increased speech processing patterns (Carr et al., 2014). And it is precisely the clapping of hands in time to music that has been studied by the National Council of Teachers of Mathematics, which can improve the learning of mathematical thinking, such as understanding fractions and whole number ratios (Johnson and Edelson, 2003).

The development of coordination skills in children, especially rhythmicity, also leads to improvements in the case of some neurodevelopmental disorders. Several studies have examined how rhythm and coordination can help in the case of dyslexia (Menghini et al., 2011). The literature showing the benefits of music training for the development of auditory skills in people and children with dyslexia is now quite extensive (BishopLiebler et al., 2014; Forgeard et al., 2008; Huss et al., 2011; Thomson and Goswami, 2008). Children with dyslexia have difficulty with word sounds, and it has recently been shown that phonological difficulties in dyslexia extend to other features, such as processing the rhythm of speech (Leong et al., 2011). The development of temporal skills through music training can be an effective tool to improve the language and literacy skills of dyslexic children (Overy, 2000). Bishop-Liebler et al., demonstrated that musical training of a group of musicians has a positive effect on some auditory processing difficulties associated with developmental dyslexia, and that musical knowledge could have beneficial effects in phonological development, especially when the rhythmic and metrical structure in music is linked to the rhythmic structure of language (Bishop-Liebler et al., 2014).

The development of rhythmic skills can also be supportive in the case of behavioural disorders such as Autism Spectrum Disorders (ASD) and Attention Deficit Hyperactivity Disorder (ADHD). In the case of ADHD, it has been shown, for example, that music is rhythm and rhythm is structure, and it is precisely a structure that can help a high-functioning brain. A structure is essential in order to strengthen attention, concentration and planning. Rhythmicity therefore helps a child with ADHD to cope with difficulties and to stay on a linear path (Jackson, 2003; Rickson, 2006; Zhang et al., 2017).

Rhythmic skills and musical listening can also help children with Autism Spectrum Disorder (ASD). In addition to providing organization, rhythmicity and music are able to give the child support in interacting with objects and people, encouraging communication (Gattino et al., 2011). Rhythm has also been shown to be a useful tool for improving the motor skills of children with autism, as they are known to have innumerable motor deficits, including movement coordination, motor planning deficits, gait abnormalities, and impaired performance of skilled motor tasks (Findlay, 1995; Frego et al., 2004; Hurwitz et al., 1975).

\section{CONCLUSIONS}

Coordinative skills are not innate and therefore should be cultivated and stimulated from an early age. Rhythmicity plays a key role among these skills and can improve various aspects of a child's everyday life. Through teaching that improves rhythmic skills through music, cognitive development on the one hand, and the development of motor skills on the other, are already evident in the early years. Furthermore, thanks to its ability to regularize movement and increase the ability to coordinate simultaneous actions, rhythmicity plays a fundamental role in stimulating cognitive and motor functions, even in people with disabilities. And it is for the reasons mentioned above that from the earliest school years, the use of an alternative teaching method that includes an improvement in rhythmic skills through music could be useful, in order to stimulate 
motor coordination and attention skills, encouraging communication and socialization in a creative and playful way.

\section{REFERENCES}

Agosti, V., Vitale, C., Avella, D., Rucco, R., Santangelo, G., Sorrentino, P., Varriale, P., Sorrentino, G., 2016. Effects of Global Postural Reeducation on gait kinematics in parkinsonian patients: a pilot randomized three-dimensional motion analysis study. Neurol. Sci. 37, 515-522. https://doi.org/10.1007/s10072-015-2433-5

Bishop-Liebler, P., Welch, G., Huss, M., Thomson, J.M., Goswami, U., 2014. Auditory temporal processing skills in musicians with dyslexia. Dyslexia 20, 261-279. https://doi.org/10.1002/dys.1479

Boreham, C., Riddoch, C., 2001. The physical activity, fitness and health of children. J. Sports Sci. 19, 915-929. https://doi.org/10.1080/026404101317108426

Carr, K.W., White-Schwoch, T., Tierney, A.T., Strait, D.L., Kraus, N., 2014. Beat synchronization predicts neural speech encoding and reading readiness in preschoolers. Proc. Natl. Acad. Sci. 111, 1455914564. https://doi.org/10.1073/pnas. 1406219111

Casolo, F., 2002. Lineamenti di teoria e metodologia del movimento umano. Vita e pensiero.

Findlay, E., 1995. Rhythm and movement: Applications of Dalcroze eurhythmics. Alfred Music.

Forgeard, M., Schlaug, G., Norton, A., Rosam, C., lyengar, U., Winner, E., 2008. The relation between music and phonological processing in normal-reading children and children with dyslexia. Music Percept. 25, 383-390. https://doi.org/10.1525/mp.2008.25.4.383

Frego, R.J.D., Gillmeister, G., Hama, M., Liston, R.E., 2004. The dalcroze approach to music therapy. Introd. to approaches Music Ther. 15-24.

Gattino, G.S., Riesgo, R. dos S., Longo, D., Leite, J.C.L., Faccini, L.S., 2011. Effects of relational music therapy on communication of children with autism: a randomized controlled study. Nord. J. Music Ther. 20, 142-154. https://doi.org/10.1080/08098131.2011.566933

Hallam, S., 2010. The power of music: Its impact on the intellectual, social and personal development of children and young people. Int. J. Music Educ. 28, 269-289. https://doi.org/10.1177/0255761410370658

Hurwitz, I., Wolff, P.H., Bortnick, B.D., Kokas, K., 1975. Nonmusicol effects of the kodaly music curriculum in primary grade children. J. Learn. Disabil. 8, 167-174. https://doi.org/10.1177/002221947500800310

Huss, M., Verney, J.P., Fosker, T., Mead, N., Goswami, U., 2011. Music, rhythm, rise time perception and developmental dyslexia: perception of musical meter predicts reading and phonology. Cortex 47, 674-689. https://doi.org/10.1016/j.cortex.2010.07.010

Hyde, K., Lerch, J., Norton, A., Forgeard, M., Winner, E., Evans, A., Schlaug, G., 2009. The effects of musical training on structural brain development. Ann. N. Y. Acad. Sci. 1169, 182-186. https://doi.org/10.1111/j.1749-6632.2009.04852.x

Jacini, F., Sorrentino, P., Lardone, A., Rucco, R., Baselice, F., Cavaliere, C., Aiello, M., Orsini, M., lavarone, A., Manzo, V., Carotenuto, A., Granata, C., Hillebrand, A., Sorrentino, G., 2018. Amnestic mild cognitive impairment is associated with frequency-specific brain network alterations in temporal poles. Front. Aging Neurosci. 10, 1-11. https://doi.org/10.3389/fnagi.2018.00400

Jackson, N.A., 2003. A Survey of Music Therapy Methods and Their Role in the Treatment of Early Elementary School Children with ADHD. J. Music Ther. 40, 302-323. https://doi.org/10.1093/imt/40.4.302

Jaques-Dalcroze, E., 2014. Rhythm, music and education. Read Books Ltd. 
Johnson, G.L., Edelson, R.J., 2003. Integrating music and mathematics in the elementary classroom. Teach. Child. Math. 9, 474-479. https://doi.org/10.5951/TCM.9.8.0474

Lardone, A., Liparoti, M., Sorrentino, P., Rucco, R., Jacini, F., Polverino, A., Minino, R., Pesoli, M., Baselice, F., Sorriso, A., Ferraioli, G., Sorrentino, G., Mandolesi, L., 2018. Mindfulness meditation is related to long-lasting changes in hippocampal functional topology during resting state: A magnetoencephalography study. Neural Plast. 2018. https://doi.org/10.1155/2018/5340717

Leong, V., Hämäläinen, J., Soltész, F., Goswami, U., 2011. Rise time perception and detection of syllable stress in adults with developmental dyslexia. J. Mem. Lang. 64, 59-73. https://doi.org/10.1016/i.jml.2010.09.003

Liparoti, M., Della Corte, M., Rucco, R., Sorrentino, P., Sparaco, M., Capuano, R., Minino, R., Lavorgna, L., Agosti, V., Sorrentino, G., 2019. Gait abnormalities in minimally disabled people with Multiple Sclerosis: A 3D-Motion Analysis study. Mult. Scler. Relat. Disord. https://doi.org/10.1016/.msard.2019.01.028

Liparoti, M., Lopez, E.T., Agosti, V., 2020. Motion capture system: A useful tool to study cyclist's posture. Menghini, D., Vicari, S., Mandolesi, L., Petrosini, L., 2011. Is learning by observation impaired in children with dyslexia? Neuropsychologia 1996-2003. https://doi.org/10.1016/i.neuropsychologia.2011.03.029

Minino, R., Lopez, E.T., Sorrentino, P., Rucco, R., Lardone, A., Pesoli, M., Tafuri, D., Mandolesi, L., Sorrentino, G., Liparoti, M., 2020. The effects of different frequencies of rhythmic acoustic stimulation on gait kinematics and trunk sway in healthy elderly population. bioRxiv. https://doi.org/10.1101/2020.11.20.390955

Minino, R., Belfiore, P., Liparoti, M., 2020. Neuroplasticity and motor learning in sport activity. J. Phys. Educ. Sport 20.

Montuori, S., D'Aurizio, G., Foti, F., Liparoti, M., Lardone, A., Pesoli, M., Sorrentino, G., Mandolesi, L., Curcio, G., Sorrentino, P., 2019. Executive functioning profiles in elite volleyball athletes: Preliminary results by a sport-specific task switching protocol. Hum. Mov. Sci. 63, 73-81. https://doi.org/10.1016/i.humov.2018.11.011

Moorhead, G.E., Pond, D., 1978. Music of young children. Pillsbury Foundation for Advancement of Music Education.

Moreno, S., Marques, C., Santos, A., Santos, M., Castro, S.L., Besson, M., 2009. Musical training influences linguistic abilities in 8-year-old children: more evidence for brain plasticity. Cereb. Cortex 19, 712-723. https://doi.org/10.1093/cercor/bhn120

Overy, K., 2000. Dyslexia, temporal processing and music: The potential of music as an early learning aid for dyslexic children. Psychol. Music 28, 218-229. https://doi.org/10.1177/0305735600282010

Palma, D. di, Tafuri, D., 2016. Special needs and inclusion in sport management: a specific literature review. Sport Sci. 9, 24-31.

Pietsch, S., Böttcher, C., Jansen, P., 2017. Cognitive motor coordination training improves mental rotation performance in primary school-aged children. Mind, Brain, Educ. 11, 176-180. https://doi.org/10.1111/mbe.12154

Rickson, D.J., 2006. Instructional and improvisational models of music therapy with adolescents who have Attention Deficit Hyperactivity Disorder (ADHD): A comparison of the effects on motor impulsivity. J. Music Ther. 43, 39-62. https://doi.org/10.1093/imt/43.1.39

Rucco, R., Liparoti, M., Agosti, V., 2020. A new technical method to analyse the kinematics of the human movements and sports gesture.

Rucco, R., Liparoti, M., Jacini, F., Baselice, F., Antenora, A., De Michele, G., Criscuolo, C., Vettoliere, A., Mandolesi, L., Sorrentino, G., Sorrentino, P., 2019. Mutations in the SPAST gene causing 
hereditary spastic paraplegia are related to global topological alterations in brain functional networks. Neurol. Sci. 40, 979-984. https://doi.org/10.1007/s10072-019-3725-y

Rucco, R., Sorriso, A., Liparoti, M., Ferraioli, G., Sorrentino, P., Ambrosanio, M., Baselice, F., 2018. Type and Location of Wearable Sensors for Monitoring Falls during Static and Dynamic Tasks in Healthy Elderly: A Review. Sensors 18, 1613. https://doi.org/10.3390/s18051613

Schlaug, G., Norton, A., Overy, K., Winner, E., 2005. Effects of music training on the child's brain and cognitive development. Ann. York Acad. Sci. 1060, 219. https://doi.org/10.1196/annals.1360.015

Seitz, J.A., 2005. Dalcroze, the body, movement and musicality. Psychol. Music 33, 419-435. https://doi.org/10.1177/0305735605056155

Sorrentino, P., Barbato, A., Del Gaudio, L., Rucco, R., Varriale, P., Sibilio, M., Strazzullo, P., Sorrentino, G., Agosti, V., 2016. Impaired gait kinematics in type 1 Gaucher's Disease. J. Parkinsons. Dis. 6, 191-195. https://doi.org/10.3233/JPD-150660

Sorrentino, P., Lardone, A., Pesoli, M., Liparoti, M., Montuori, S., Curcio, G., Sorrentino, G., Mandolesi, L., Foti, F., 2019. The development of spatial memory analyzed by means of ecological walking task. Front. Psychol. 10. https://doi.org/10.3389/fpsyg.2019.00728

Thomson, J.M., Goswami, U., 2008. Rhythmic processing in children with developmental dyslexia: auditory and motor rhythms link to reading and spelling. J. Physiol. 102, 120-129. https://doi.org/10.1016/j.jphysparis.2008.03.007

Troisi Lopez, E., Minino, R., Sorrentino, P., Rucco, R., Carotenuto, A., Agosti, V., Tafuri, D., Manzo, V., Liparoti, M., Sorrentino, G., 2021. A synthetic kinematic index of trunk displacement conveying the overall motor condition in Parkinson's disease. Sci. Rep. 11, 1-11. https://doi.org/10.1038/s41598$\underline{021-82348-4}$

Weineck, J., 1983. Manuel d'entraînement.

Wickstrom, R.L., 1975. Developmental kinesiology: Maturation of basic motor patterns. Exerc. Sport Sci. Rev. 3, 163-192. https://doi.org/10.1249/00003677-197500030-00009

Zentner, M., Eerola, T., 2010. Rhythmic engagement with music in infancy. Proc. Natl. Acad. Sci. 107, 5768-5773. https://doi.org/10.1073/pnas.1000121107

Zhang, F., Liu, K., An, P., You, C., Teng, L., Liu, Q., 2017. Music therapy for attention deficit hyperactivity disorder (ADHD) in children and adolescents. Cochrane Database Syst. Rev. 2017. https://doi.org/10.1002/14651858.CD010032.pub2 